\title{
Didactical Design on Drawing and Analysing Trigonometric Functions Graph through a Unit Circle Approach
}

\author{
Churun Lu'lu'il Maknun ${ }^{1,2,3^{*}}$, Rizky Rosjanuardi ${ }^{3}$, Al Jupri $^{3}$ \\ ${ }^{1}$ Institut Agama Islam Negeri Ponorogo, INDONESIA \\ 2 Universitas Wahidiyah, INDONESIA \\ ${ }^{3}$ Universitas Pendidikan Indonesia, INDONESIA \\ *CORRESPONDENCE: $\triangle$ churun29@ymail.com
}

\begin{abstract}
A Trigonometric function is one of the challenging materials for not only high school students but also pre-service teachers and teachers. On the other hand, An understanding of trigonometric function is an initial stage in understanding calculus derived from it such as limit, derivative, and integral. Thus, the competency in trigonometric function is an issue need further discussion. This is a qualitative study which elaborated the didactical design and the class observation of high school student. In this study, we propose a didactical design with the aim to figure out the properties of trigonometric functions. Starting from drawing the graph then analyse each of the graphs. We used the trigonometric function graph as a media to analyse the function such as trigonometric value, maximum and minimum, period, and interval in which it decreases or increases. The two main aims in this study are: 1) How the unit circle is used for drawing trigonometric function graph, 2) How the trigonometric function graph can be used to analyse the trigonometric function properties. The study shows that the students can follow the learning sequences both in drawing and analysing the graph. The misconception of trigonometric values is figured out. Some unpredictable findings are also described in this study.
\end{abstract}

Keywords: classroom activity, didactical design, task design, trigonometric function graph, unit circle

\section{INTRODUCTION}

Trigonometry has enormous materials related to various mathematics subjects. For instance, it relates to geometry, arithmetics, algebra, and calculus, particularly the study about function. These wide ranges materials of trigonometry are studied by the students since high school. In school, the students learn about two contexts of trigonometry i.e. trigonometry as a study related to geometry which is specifically known as trigonometry as a ratio of the length side of the right-angle triangle, and trigonometry as a study related to calculus which is specifically known as a trigonometric function. Trigonometry as a ratio of a right-angle triangle is defined as the ratios of either the opposite or adjacent side of a right-angle triangle over hypotenuse which is widely known as: $\sin =\frac{\text { opposite }}{\text { hypotenuse }}$ and $\cos =\frac{\text { adjacent }}{\text { hypotenuse }}$. Further, trigonometric law such as sine and cosine law and the application of trigonometry are derived from this definition. On the other hand, trigonometric function talks about trigonometry as a function which has domain, range, and properties of function and uses radian as its measure (Maknun, Rosjanuardi, \& Jupri, 2018). The properties of a trigonometric function is an initial stage to analyze limit, derivative and integral of trigonometry in calculus

Article History: Received 31 December 2019 • Revised 22 July $2020 \bullet$ Accepted 23 August 2020

(C) 2020 by the authors; licensee Modestum. Open Access terms of the Creative Commons Attribution 4.0 International License (http://creativecommons.org/licenses/by/4.0/) apply. The license permits unrestricted use, distribution, and reproduction in any medium, on the condition that users give exact credit to the original author(s) and the source, provide a link to the Creative Commons license, and indicate if they made any changes. 
since development of trigonometric functions are based on some concept in analysis (Corlis \& Berglund, 1958; Spitzbart \& Bardell, 1955; Varberg, Purcell, \& Rigdon, 2006)

Studies show that the concept of trigonometry as a ratio of side right-angle triangle is well understood by the students. Both teacher and students have a minor complication in this concept compared with the other concept i.e trigonometry as a function (Byers, 2010; Cetin, 2015; Maknun, Rosjanuardi, \& Ikhwanudin, 2018; Weber, 2005). The use of ratios approach in trigonometry generally emphasizing procedural skills and such expertise does not give students an understanding of trigonometric functions (Usman \& Hussaini, 2017; Walsh, Fitzmaurice, \& O Donoghue, 2017; Weber, 2005). Too much emphasis on trigonometry as a ratio of right-angle triangle sides will take a long time for students to learn trigonometry as a function logically and systematically (Usman \& Hussaini, 2017). Maknun, Rosjanuardi, and Ikhwanudin (2018) reveal the student study trigonometri and its value only particularly at at a special angle. The concept of trigonometry as a function had been overlooked and students had limited understanding about it, for instance, the students are difficult to recognize in which range the sine and cosine function is either decrease or increase (Kamber \& Takaci, 2017; Weber, 2008) whereas knowing this concept could help them mastering the limit, differential, and integral of trigonometry.

Studies showed that a unit circle can bridge the gap between student's knowledge of trigonometry as a ratio of a right-angle triangle and trigonometry as a function (Demir \& Heck, 2013; Maknun, Rosjanuardi, \& Jupri, 2019). On the other hand, the obstacle arose could be because students are not ready with the material provided or the material taught is too abstract for them (Orhun, 2001). Graphical representation can provide a visual representation which can help the students (Choi-koh, 2003). Trigonometric function graph as one of the representations of trigonometry as a function visibly explores the properties of trigonometry. Thus, the collaboration of the unit circle concept which had been revealed can be suitable approach in trigonmetric function and the need of real object as trigonometric graph. As Kansanen and Meri (1999) study that class situation is an interactive interaction among students, teacher, and material which a complex system knowledge construction. Since material is a vital component in didactical situation, Park (1994) shows the role of simulations that can bring students' attention to important features and their relationships with other components that may not be easily understood in abstract systems. Simulation can also illustrate procedural relationships, address the issue or problem arising in the simulation (Gredler, 2004) . For example, when changing a trigonometric graph that involves four transformations, students can see sequential steps to achieve the final result. As Gredler (2004) mentions that it bridges the gap between the classroom and the real world by providing experience with complex, evolving problems. It also can reveal student misconceptions, understandings about the content and provide information about students' problem solving strategies. This purpose is in line with the TDS by Brousseau (2002) as a adidactical situation, a situation includes both the task and the environment which include problem to be posed, the conditions under which it is to be solved, and the expected progression toward a strategy in order to develop student's mathematical knowledge. The didactical design proposed is not only showing the interaction prosess in class but also framing within a deep a priori analysis of the underlying materials of the topic to be learned, integrating the epistemology of the materials, and supporting cognitive hypotheses related to the materials (Brousseau, 2002). Hence, the teachers could make a suitale design for their students, how to expose the connection among the mathematics materials and minimize the learning obstacle for students.

The didactical design in this study is proposed to figure out the trigonometric function graph through a unit circle approach. This study is guided by the following research questions:

1. How didactical design in drawing trigonometric functions through unit circle approach?

2. How didactical design in analysing trigonometric function properties through graphical representation?

The practical implication of this study can be an input for teachers and other researchers to implement it again in mathematics learning. This study proposes mathematics learning trajectory, for example how the presentation of material topics is given and how the sequence and interrelation between topics in order to obtain a continuous learning sequences.

\section{THEORETICAL FRAMEWORK}

\section{Didactical Design}

Didactics is as being about the transformation of the subject (mathematics) through activities and tasks in which students can gain access to mathematics, engage with mathematics, and come to know the 
mathematical concept (Sullivan, Knott, \& Yang, 2015). In order to acquire this, the role of the teacher is to select, modify, design, redesign, sequence, implement, and evaluate the tasks. These task activities offer students to encounter mathematical concepts, ideas, and strategies. Factors that influence the task design process and accompanying pedagogical considerations are: 1) The interactions among aspects of task design: design elements of tasks, the nature of the mathematics that is the focus of the tasks, and the task design processes; 2.) Pedagogies: the nature of the authority and autonomy of the teacher in creating and implementing tasks and problematic aspects of converting tasks from one culture to another. 3) Students learning: consideration of students' responses in anticipating the pedagogies (Sullivan et al., 2015)

These two different ways (mathematical knowledge and situations) are related to epistemological analysis. From this epistemological analysis it forms, which Brousseau called, the theory of mathematical situations and didactical situations (in this study called didactic situations). Didactic situations, namely situations that are designed and utilized according to the objectives of teaching and learning (Artigue et al., 2014). Brousseau (2002) distinguish two perspectives that might occur in a didactic situation, the first view of the student environment organized by the teacher, and the second a broader view that includes the teacher and the education system itself.

\section{Theory of Didactical Situation}

Theory of didactical situation (TDS) is associated with Guy Brousseau (Watson, 2015). A first synthesis of TDS was published in 1997 in English but the theory has since developed considerably in its conceptual notions as much as its research methodologies (Artigue, Haspekian, \& Corblin-Lenfant, 2014). In this study The Theory of Didactical Situations (TDS) was used as framework in how the didactical design should be conducted. The characteristic of TDS research are: 1) framing within a deep a priori analysis of the underlying materials of the topic to be learned, 2) integrating the epistemology of the materials, and 3) supporting cognitive hypotheses related to the materials (Brousseau, 2002). Framing within a deep a priori analysis of the underlying materials of the topic to be learned is its attention to mathematics and its epistemology which is stated in two different ways, namely through the epistemological situation and through the fundamental situation of a given concept (Artigue et al., 2014). Epistemological situation is related to providing a form of knowledge that is relevant and successful in certain concepts, but sometimes becomes incorrect or inadequate. While, the fundamental situation of a given concept is mathematical situations in which the concept given forms the optimal solution.

Integrating the epistemology of the materials is related to the epistemological characteristics of mathematical knowledge. This characteristic is reflected in three types of situations, namely action, formulation and validation (Brousseau, 2002).

1) The action situation is how students determine the strategy, it means how students develop strategies to deal with and respond to given problems; analyze and understand problems

2) Formulation situation is a situation where students interact with their friends, argue and make conclusions.

3) Validation situation is a situation that asks students to develop, to correct, to revise opinions, conclusions analyzes made by students.

Supporting cognitive hypotheses related to the materials is related to the cognitive dimensions of students, especially in the process of adaptation and acculturation. The concept of adaptation is in accordance with the concept of Piaget (1970) that students learn by adjusting themselves and their environment that in the process there will be contradictions, differences, imbalances which are natural processes as experienced in the social conditions of society. The results of this student adaptation make evidence of the learning process (Brousseau, 2002). While the concept of acculturation is needed to connect the construction of students with the knowledge they have. Adaptation and acculturation are two key construction processes in TDS (Artigue et al., 2014). The key constructs of adaptation, in TDS, are referred to as a-didactical situation-situations that arise outside the context of the learning plan (Brousseau, 2002) and milieu-conditions and events in which students interact in a-didactical situation, and are roles teacher in arranging this (Artigue et al., 2014).

While the key construction of acculturation, in TDS, through the term devolution (the teacher makes students accept mathematical responsibilities through problem solving without expressing the conclusions of learning first) and institutionalization (the teacher helps students in connecting the knowledge that students have built in a-didactical situation). The teacher need in fostering the later institutionalization of the students' mathematical knowledge acquired during the adidactical phase-the term institutionalization referring 
specifically to the process whereby the teacher gives a certain status to the ideas developed by students by framing and situating them within the concepts and terminology of the broader cultural body of scientific knowledge (Artigue, 2009; Artigue et al., 2014). Identifying a suitable set of problem situations that can support the development of new mathematical knowledge is absolutely central to the design of a TDS teaching sequence.

\section{Didactical Triangle}

The more diverse actions provided by the teacher, the more diverse learning situations that will be created that will lead to increasingly complex learning processes. The complexity of learning is related to the interaction among teacher, students, and material. Kansanen (2003), and Kansanen and Meri (1999) use didactic triangles to facilitate understanding the complex relationships between teacher, students, and material i.e. the relationships between teacher and students (pedagogical relationship); between teacher and material; and between students and material (didactical relationship). The relationship between the teacher and the students relates in the form of intervention from the teacher, scaffolding, actions taken by the teacher to create a learning situation so that the learning process can be formed (Suryadi, 2010). When the teacher take action on the students (for example in the form of instruction) the students will take action, where the students' action determines the teacher' next action and so on. So that in this case, the relationship that occurs between teacher and students is a two-way relationship.

The relationship between students and material is the key to didactic understanding (Kansanen, 2003; Kansanen \& Meri, 1999). This is because the entire learning process boils down to the achievement of learning objectives contained in the curriculum, namely material. As the output is in the form of learning outcomes, but not limited to that. Behavior change as a result of the response to activities during the learning process is also a consequence of the output of the learning process. This learning process can be seen and observed in the learning process. In other words, the relationship between students and material can look like the learning process. However, there are things that are not visible, such as the processes that occur in students' thinking as a result of relation between the students and material where this cannot be controlled by the teacher. The thing that might be done by the teacher is controlling the activities to achieve the learning goals (Kansanen, 2003; Kansanen \& Meri, 1999). Therefore, the teacher job is to direct this relationship (students and material). So, there is a relationship between students and material materialized in the activity, then the teacher has a connection in the relationship between students and material. This relationship is called the didactic relationship, the relationship between other relationships (see Figure 1).
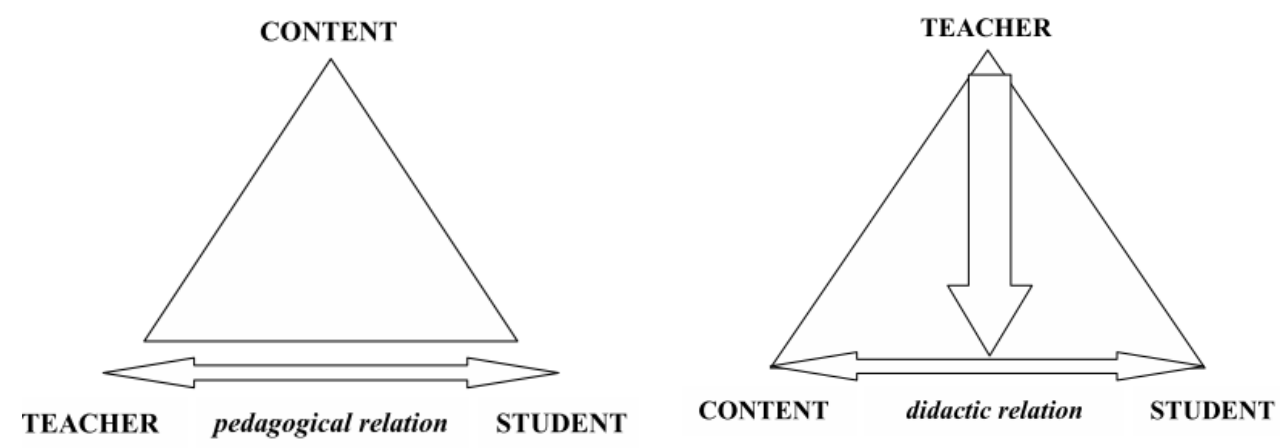

Figure 1. Didactical and pedagogical relation in didactic triangle (Kansanen \& Meri, 1999)

The relationship between the teacher and the material relates to the competence of the teacher in mastering the material. Related to this, McClellan (Kansanen \& Meri, 1999) revealed that a teacher must have what students do not have. This can be interpreted in terms of skill and academic adequacy. This can be interpreted in terms of skill and academic adequacy. It is very important that the relationship between teachers and material comes from many directions. It means that the teacher is able to view material from many sides and approaches. The relationship between the teachers and the material is something that cannot be ignored from the didactic triangle. In this relationship, the teacher predicts the learning situation while anticipating situations and students' responses that might occur. Anticipation is not only about the relation between the students and material, but also the relationship between teachers and students both individually and in groups or classes. So that it can be said that this relationship is the embodiment of the results of the teacher's thinking about a learning process by considering various possibilities that are predicted to occur in learning and learning barriers (Suryadi, 2010). Thus, it takes place before the learning process begins. To sum 
up, the main role of the teachers in this didactic triangle concept is to create a didactical situation so that there is a learning situation. In other words, a teacher needs to have the ability to create didactical relations between students and teaching material so as to create an ideal didactic situation for students (Ruthven et al., 2009).

\section{RESEARCH METHOD}

\section{Design}

The research design used in this study is qualitative. To construct didactical design, trigonometric test and interview were conducted. To get the general information in how the teaching was done, analysing of class observation and students' solution were provided. The case study approach was used in order to get in-depth information about a particular student's obstacle. In this context, the case study was choosed since it can explore .

This study is a qualitative study design and uses Didactical Design Research (DDR) method. DDR is a series of research processes that focus on how to design learning activities. The main purposes are to deliver ideas to the teacher on how to make adaptations according to the situation in the classroom, to review, and to analyze the complexity of learning through reflection practices. The didactic design research has three stages i.e. a prospective analysis, a metapedadidactics analysis and a retrospective analysis (Suryadi, 2010).

1) A prospective analysis is an analysis carried out before learning is done. We conducted an observation of the class, literature review about the topic, preliminary interview with the the senior students who had learned the material in previous academic year. The purpose of this stage was to decide what suitable learning design will be made, what kind of the learning sequences, the learning trajectory regarding the topic in the trigonometric graph. The didactical design was constructed at this stage

2) Metapedadidactics analysis was conducted to investigate the implementaion of the didactical design, to look at the learning situation comprehensively, to identify important things that occured (Suryadi, 2010).

3) Retrospective analysis aimed to reflect the learning process and analyze the possibility of learning obstacle that might be happening in the implementation process. At this stage, the revised didactical design might be proposed from the previous one.

The process of constructing didactical design was not ended to those three stages, the process could be repeated as the misconseptions were found.

\section{Participant}

This study was carried out to the grade 10th senior high school students in Indonesia public school. A total of 65 students were participate din this study. It means that they can follow mathematics learning though they are not skilled enough in analyzing and exploring mathematical questions. The data obtained in this study were obtained through four ways, i.e. interviews, class observations, documentation, and students' work results which were collected in research notes, audio recordings, video recordings, and photographs. The results of students' work, both individuals and groups will be analyzed to see students' mistakes and understanding.

\section{Data Collection and Analysis}

Various data collection were used to increase validity of the data (Creswell, 2013). Engaging in an initial exploration of the data, develop general picture of the data, representing the finding through naratives and visuals, making an interpretation of the meaning of the results by reflecting personally on the impact of the findings and on the literature that might inform the findings, conducting triangulation to validate the accuracy of the findings (Creswell, 2012). In this study, the data were obtained in three ways i.e. interviews, classroom observations and documentation. The following are the data collection techniques used in this study:

1. In this study, informal interviews were conducted in classroom setting, which means there was no question prepared The interview was conducted for particular didactical situation in which need further exploration in a group of students. In deciding which group interviewe, it was depend on the their responses to the task. The interview ended when the data were obtained either in reserach note or video recording. 
2. The observation was carried out to find in-depth findings and have a broad scope so as to strengthen the consistency and validity of research findings (Creswell, 2013). In this study, observations were made at the time of doing the didactic analysis. The observation was collected in reserach note and video recording.

3. Documentation studies conducted in this study included the results of recorded interviews, notes during the study, photos of student work and videos of the implementation of the didactical design

In this study there are five stages of the process carried out after the data collection process was done i.e. preparing data, reading the entire data, analyzing in more detail, determining the theme to be analyzed, describing the theme and interpreting the data (Torrance, 2010). Preparing data; included collecting documentation and literature results, read the overall data; looked at the data obtained in general, analyze in more detail, re-reading the data that has been marked in more detail, determine the trigonometric functions to be analyzed, describe the theme and understanding data either didactical process or didactical situation will be interpreted based on the relationship with previous studies. The didactical design in this study was divided into several situations in which for each situation, the analysis was connected to the learning situation theory in (Brousseau, 2002; Kansanen \& Meri, 1999; Simon, 1995). The larning situation was guided with the students' worksheet as shown in Table 1.

In writing the results of the analysis, researchers use a narrative approach. This approach includes a discussion of how learning activities are carried out, important events that occur in the field, and the connection between one event and another, for example how previous learning affects student actions on other learning. Researchers also present images of student work and illustrate how learning activities take place to help present the results of the analysis. The process of analyzing interview data is done by reading the entire interview transcript that has been written based on recordings from the audiotape. The observation analysis process was carried out by reviewing the learning videos and notes during the study. The things that are the focus of the main study of the study are the main things to be analyzed but the researcher does not rule out the possibility of an analysis outside the focus of the research study found during the research process that is considered important.

\section{Instrumentation}

Table 1. Guiding Question in Analysing Trigonometric Function Graphs

\begin{tabular}{|c|c|c|}
\hline Topic & Questions & \\
\hline & Sine and Cosine & Tangent \\
\hline $\begin{array}{l}\text { Maximum } \\
\text { and } \\
\text { minimum } \\
\text { value }\end{array}$ & $\begin{array}{l}\text { Consider the sine and cosine function graph } \\
\text { you drew. } \\
\text { 1. What is the maximum and minimum } \\
\text { value of } y=\sin x \\
\text { 2. What is the maximum and minimum } \\
\text { value of } y=\cos x\end{array}$ & $\begin{array}{l}\text { Consider the sine and cosine function graph you drew. } \\
\text { 1. What is the tangent value when the angle is } \frac{\pi}{2} \text { ? Why this } \\
\text { happen? Try to analyze from the definition of tangent! } \\
\text { 2. Is/Are there any angle(s) which has same value as } \tan \frac{\pi}{2} \text { ? }\end{array}$ \\
\hline$\overline{\text { Period }}$ & $\begin{array}{l}\text { 1. Do the sine value are repeated? If yes, in } \\
\text { what interval the graphs is repeated? } \\
\text { 2. Do the cosine value are repeated? If yes, } \\
\text { in what interval the graphs is repeated? }\end{array}$ & $\begin{array}{l}\text { 1. In what other interval(s) do/does the tangent graph has } \\
\text { same representation as number } 3 \text { ? (mention two other } \\
\text { intervals) }\end{array}$ \\
\hline $\begin{array}{l}\text { Increasimg } \\
\text { and } \\
\text { decreasing } \\
\text { function }\end{array}$ & $\begin{array}{l}\text { 1. If } x \text { moves from } 0 \text { to } \frac{\pi}{2}, \text { then }(\sin x / \cos x) \\
\text { value will be (decrease/ increase) from }(\ldots) \\
\text { to (...) } \\
\text { 2. If } x \text { moves from } \frac{\pi}{2} \text { to } \frac{3}{2} \pi, \text { then }(\sin x / \cos x) \\
\text { value will be (decrease/ increase) from (...) } \\
\text { to (...) } \\
\text { 3. (the analyze continue to other interval) }\end{array}$ & $\begin{array}{l}\text { 1. Compare the graph between the interval } 0 \leq x \leq \frac{\pi}{2} \text { and } \pi \leq \\
x \leq 1 \frac{1}{2} \pi \text {. Does it has same representation? } \\
\text { 2. In which other interval does the tangent graph has same } \\
\text { representation as number } 1 \text { ? (mention two other intervals) } \\
\text { 3. Compare the graph between the interval } \frac{1}{2} \pi \leq x \leq \pi \text { and } \\
1 \frac{1}{2} \pi \leq x \leq 2 \pi \text {. Does it has same representation? }\end{array}$ \\
\hline & $\begin{array}{l}\text { Without finding the value of either sine or } \\
\text { cosine, compare the value by giving the sign of } \\
>\text { or }<\text { to the questions below and explain your } \\
\text { reason! (Hint : Use trigonometry graph) } \\
\text { 1. } \sin \frac{\pi}{6} \ldots \ldots \sin \frac{\pi}{3} \\
2 . \sin \frac{7 \pi}{6} \ldots \ldots \sin \frac{3 \pi}{4} \\
3 . \quad \sin 3,24 \ldots \ldots \sin (-1) \\
4 . \quad \cos \frac{8 \pi}{3} \ldots \ldots \cos \frac{7 \pi}{4} \\
5 . \quad \cos \left(-\frac{\pi}{3}\right) \ldots \ldots \cos \left(-\frac{13 \pi}{6}\right)\end{array}$ & \\
\hline
\end{tabular}




\section{RESULT AND DISCUSSION}

\section{Prospective Analysis}

The learning process is dynamic because what is conveyed in class will affect the students' subsequent understanding as well as the assignments given to students. Mistakes that students make may not be because of the students themselves but because the learning process that is taking place does not provide an opportunity for students to obtain mathematical knowledge as they should. Analyzing the trigonometric graph can get them to retain the understanding in the trigonometric properties such as the maximum and minimum values, the period of the function,, increasing and decreasing function. Designing how the learning sequences conducted is a part of prospective analysis. The didactical design was divided into two sections i.e. drawing and analysing trigonometric function section. In each section was constructed a number of didactical situation along with the cognitive hyphoteses as a related factor in designing didactical process (Simon, 1995). The cognitive hyphotesis for drawing trigonometrics graph in this study is provided in Table 2, followed by the explanation the steps to draw the trigonometric functions.

Table 2. Didactical Situation and Cognitive Hyphoteses in Drawing Trigonometric Function

No Situation Cognitive hyphoteses

1 Determine the representation of sine and cosine based Student is able to determine the coordinates of on the coordinates of the $\mathrm{P}$ point on the circle with an angle $\alpha$.

the point $\mathrm{P}$, namely $\mathrm{P}(\cos \alpha, \sin \alpha)$

Student reverse in determine the coordinate of $\mathrm{P}$ as $(\sin \alpha, \cos \alpha)$

2 Draw the sine function from the representation of - The student needs time in relating the angles and sine values in unit circle to the cartesian concept from unit circle definition into graph coordinate and connect them in a smooth curve. representation

3 Draw the cosine function from the representation of - The student is able to both relate the cosine angles and cosine values in unit circle to the cartesian definition in unit circle into the graph and coordinate and connect them in a smooth curve. connet the graph in smooth curve

$4 \quad$ Determine the representation of tangent value in unit - The student has difficulty in recalling the circle then draw it in cartesian coordinate and connect concept of triangle congruent them in a smooth curve..

- The student has difficulty in connecting the points into smooth curve

- The student has difficulty in finding the value when $x=\frac{\pi}{2}$

The idea of drawing the trigonometric function graph is transferring from a unit circle to a cartesian plane. In this study, we did not limit the angle for some special angles but any angle, both positive and negative, smaller than $90^{\circ}$ and greater than $90^{\circ}$. To make it easier for students, thus, the unit circle had been divided into sixteen regions (the more regions are better).

The procedure to draw sine and cosine function as shown in Figure 2 is explained as follows: 


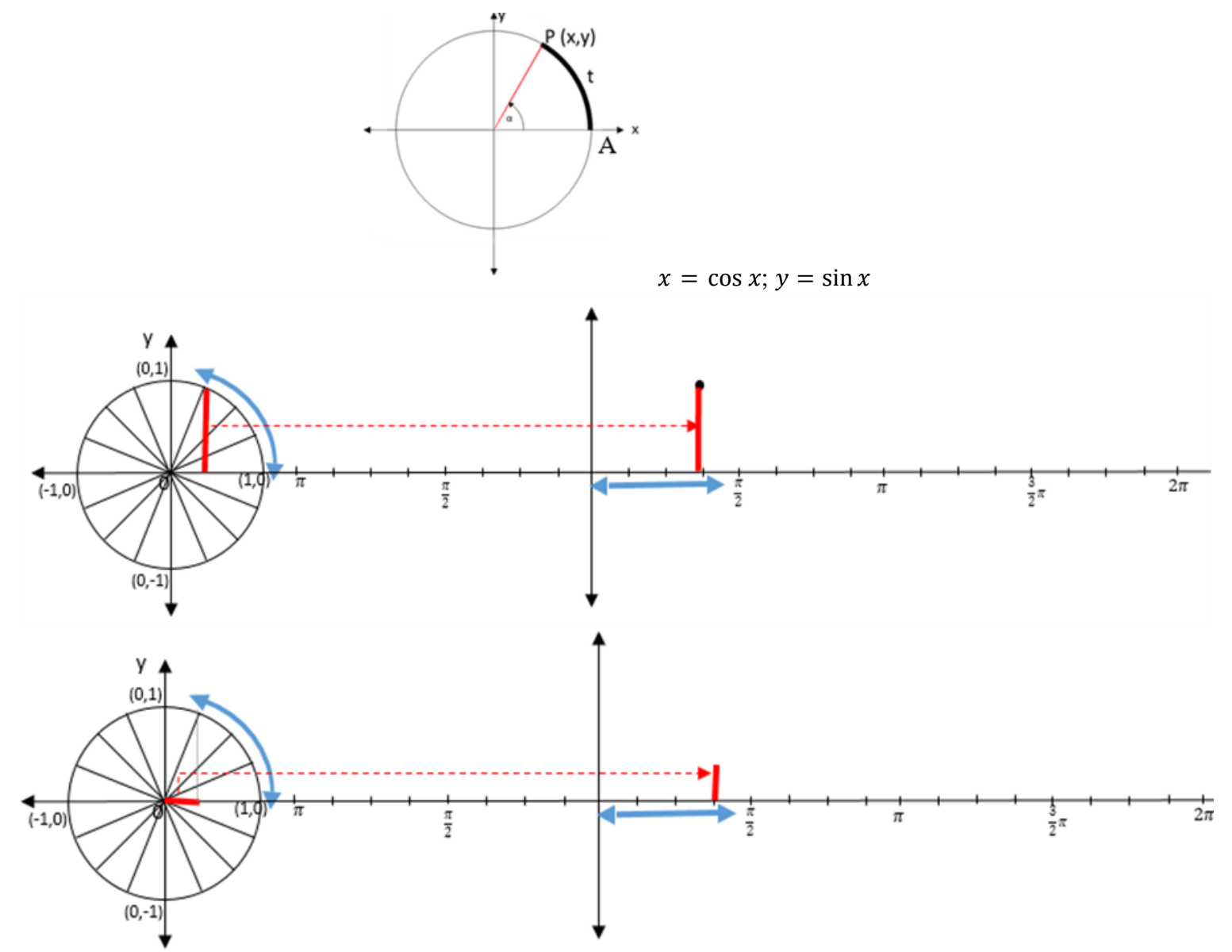

Figure 2. Process in Drawing Sine and Sosine Function from Unit Circle

1) Measuring the length of the arc in each angle for each region of a unit circle then transfer it to the $x$ axis. This length represents the domain of the sine function. There is no need for students to know the exact value of measure thus the students thus the students can use thread to know the length of the arc.

2) Measuring the length of the vertical line segment obtained from each point on the circle perpendicular to the $x$-axis. This length represents the range of sine function. There is no need for students to know the exact value of measure thus the students can use either a compass or a ruler to know the length of it

3) Corresponding the length of the arc (in step one) to the length of the vertical line segment (step two). These steps are continued for both negative and positive angle, the obtuse angles, and angles more than $2 \pi$.

4) Then connect the points formed in a smooth curve.

5) To draw a cosine function graph, the different step is in step two, instead of measuring the vertical line segment in drawing cosine function the students need to measure the horizontal line segment obtained from each point on the circle that perpendicular to the y-axis. This length of the line segment is the range of cosine function.

The procedure to draw tangent function graph is explained by its definition. A tangent is the ratio of sine and cosine function. Since both sine and cosine are a function thus the tangent is also a function. Unlike sine and cosine, in which their representation is easily known from the point coordinates in a unit circle. In tangent, it needs further development to determine the right representation. To draw the representation of the tangent value in a unit circle, the students were asked to to construct it by the definition of the tangent (see Figure $3)$. 


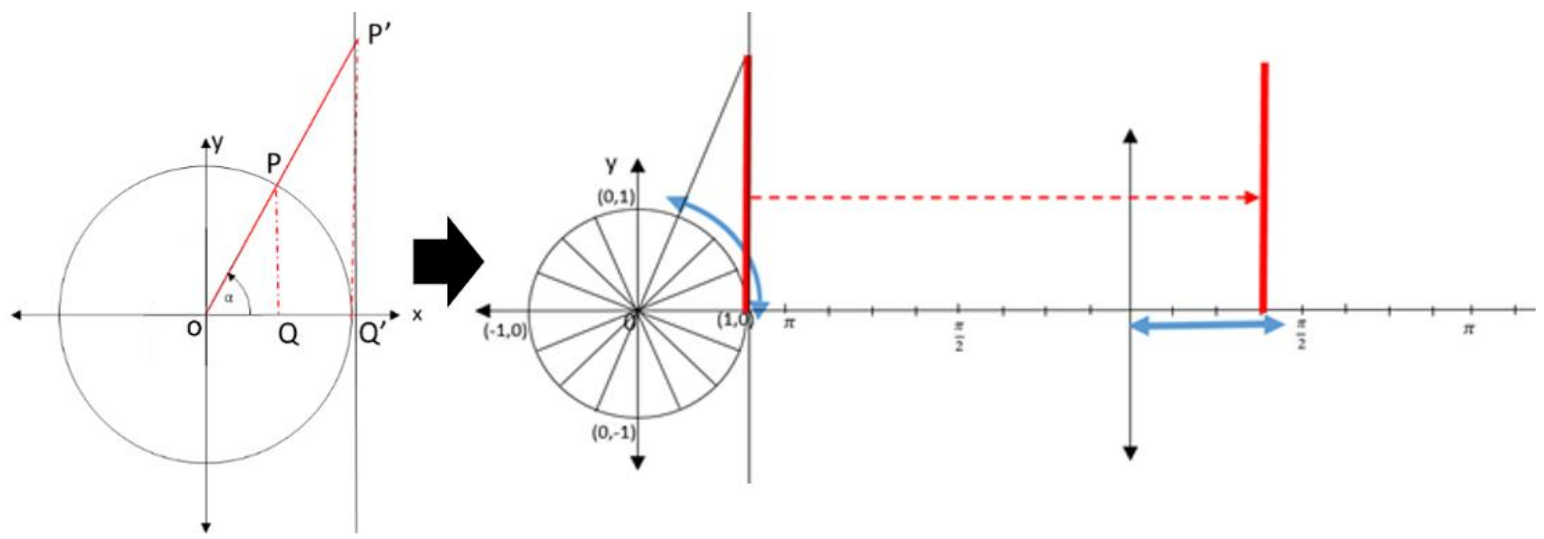

Figure 3. Representation of Tangent on a Unit Circle

1) Consider the $\alpha$ in a unit circle with the center in $O$. Line segment $\overline{O P}$ intersects the unit circle at the point $P$ in the coordinate of $P(\cos \alpha, \sin \alpha)$.

2) $\overleftrightarrow{P^{\prime} Q^{\prime}}$ is a given-line which tangent to the circle at the point $(1,0)$.

3) Considering that $m \angle Q O P=m \angle Q^{\prime} O P^{\prime}=\alpha, m \angle O Q P=m \angle O Q^{\prime} P=90^{\circ}$ thus $m \angle O P Q=m \angle O P^{\prime} Q^{\prime}$. Hence, the triangle $P O Q$ and $P^{\prime} O Q^{\prime}$ have the corresponding angles. This applies $\frac{O Q}{O Q^{\prime}}=\frac{O P}{O P^{\prime}}=\frac{P Q}{P Q^{\prime}}$ thus $\tan \alpha=$ $\frac{\sin \alpha}{\cos \alpha}=\frac{P Q}{O Q}=\frac{P \prime Q^{\prime}}{O Q^{\prime}}$.

4) Since $\overline{O Q^{\prime}}$ is the radius of the unit circle, one unit length, thus the value of $\tan \alpha$ is equal to the line segment $\overline{P^{\prime} Q^{\prime}}$.

5) Thus, to find the tangent value in a unit circle can be obtained by measuring the line segment of $\overleftrightarrow{P^{\prime} Q^{\prime}}$ which is intersected by the extension of two rays of $\alpha$.

6) After knowing the tangent representation in the unit circle, the next step is to draw a tangent function graph based on a unit circle (see Figure 4). The process of drawing a tangent graph begins by drawing an extension of the end of an angle on a unit circle so that it intersects the tangent of the circle then corresponds to each angle with the tangent value.

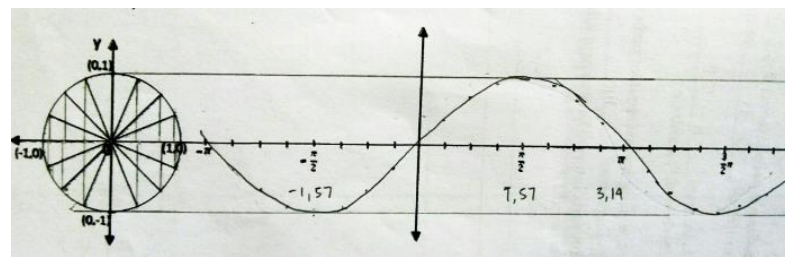

(a)

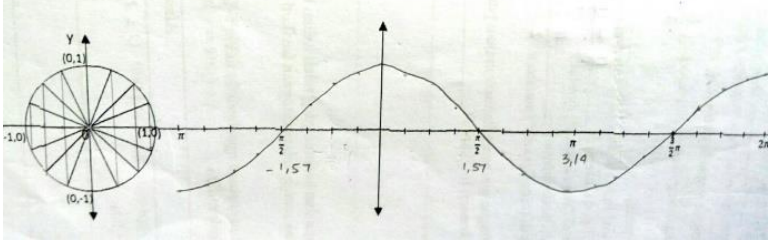

(b)

Figure 4. Student's works in drawing graph of (a) $y=\sin (x)$ and (b) $=y=\cos (x)$

The didactical design for analysing trigonometrics graph was started by answering the question in student worksheet related to the trigonometric function properties (see Table 1) based on the trigonmetric graphs. The didactical situation and cognitive hyphotesis for each situation is provided in Table 3 .

Table 3. Didactical Situation and Cognitive Hypotheses in Analysing Trigonometric Functions

\begin{tabular}{lll}
\hline No & Situation & Cognitive Hypohoteses \\
\hline 1 & $\begin{array}{l}\text { Analysing maximum and minimum } \\
\text { property }\end{array}$ & $\begin{array}{l}\text { - The students will have no difficulty in sine and cosine } \\
\text { function however, the student will have difficulty in tangent } \\
\text { function since it has different representation graph }\end{array}$ \\
\hline 2 & $\begin{array}{l}\text { Analysing period of trigonometric } \\
\text { function }\end{array}$ & $\begin{array}{l}\text { - The students will have no difficulty in sine, cosine and } \\
\text { tangent functions }\end{array}$ \\
\hline 3 & $\begin{array}{l}\text { Analysing increasing and decreasing } \\
\text { function in trigonometric function }\end{array}$ & $\begin{array}{l}\text { - The students will find no difficult in deciding increasing and } \\
\text { decreasing function in sine, cosine and tangent. }\end{array}$ \\
\hline
\end{tabular}




\section{Metapedadidactic Analysis}

Classroom practice encompasses the teachers' teaching and organisation of students' learning as well as students' learning activities. Interpretating classrroom activities is not only trying to explain why things go wrong, or why thing goes very well but also understanding the complex interplay between factors on different levels that makes up the daily teaching routines, providing certain patterns that are well known from so many classroom. There are several factors that ralate to the classroom activities i.e direct relation such as social relations in the classroom, student relations, relations between teacher and students, students' prerequisites for learning, technical and material equipment and indirect relation such as national curriculum plans (Imsen, 1999). This section highlights the student's response to the didactical situation given by teacher as part of metadidactical and retrospective analysis.

\section{Students' response in drawing the graph}

There is no significant difficulty for students in drawing sine function and they could connect and relate to the unit circle. In this case, the students can be clasified as have understanding the process in drawing sine function graph (Bruner, 1966). Figure 4 shows the learning process when drawing the cosine function graph relied on the learning process in drawing a sine function graph since it has similarity.

The epistemological characteristics of mathematical knowledge were shown in drawing sine and cosine function such as the action situation which reflect on how the students develop strategies to deal with and respond to drawing the graph from the unit circle definition and formulation situation which reflect on the interaction among the students to make conclusion that they also can draw the graph in negative $\mathrm{x}$-axis as well as angles larger than $360^{\circ}$ (Brousseau, 2002). The findings in how student draw the trigonometric function is summarized at Table 4.

Table 4. General Findings in Drawing Trigonometric Functions

\begin{tabular}{lll}
\hline No & Functions & Findings / area of challenge \\
\hline 1 & Sine & - Can relate and connect from unit circle to graphical representation \\
& & - explore positive angles, particularly focus on $0^{\circ}$ to $360^{\circ}$ \\
& & - the graph making process of sine functions greatly influences students in the process \\
& & of making cosine function graphs. \\
\hline 2. & Cosine & - Compared with sine gragh, need shorter time in drawing sine graph \\
& & - Some students connect the dots in linier line instead of smooth curve line. \\
& & - exlore negative angles and angles more than $360^{\circ}$ \\
\hline 3 & Tangent & - Getting confuse in particular angle such as $\frac{\pi}{2} r a d$ \\
& & - Difficulty in correspond the representation for angles in second and fourth quadrant. \\
& & - Learn the term of 'asymptote'
\end{tabular}

Table 4 shows that the students who encounter difficulty in drawing a sine function graph so much likely also difficult in drawing cosine function graphs. For instance, we found while graph making process, some students connected the points in the cartesian plane in a straight line instead of connected it in a smooth curve line because he did the same in the sine function graph (see Figure 5). This finding was in line with Ausubel (1968) and Bruner (1960) that an understanding of a student's prior knowledge determined the appropriate starting point for instruction. The trend is in the process of creating cosine graphs as a result of the graph making process of the sine function graph. Likewise, if an error is found in the process of making a cosine graph, it might also be related to the error students make in the graph making process of the sine function graph. This response is same as Kagenyi (2016) finding as the most challanging factor in drawing the graph. In this situation student experienced acculturation process as they connect the construction process in drawing sine function to the constraction process in drawing cosine function which is a key role in TDS (Brousseou, 2002). Making sure that students have fully understand the sine function graph will make significant contribution in the acculturation process. 


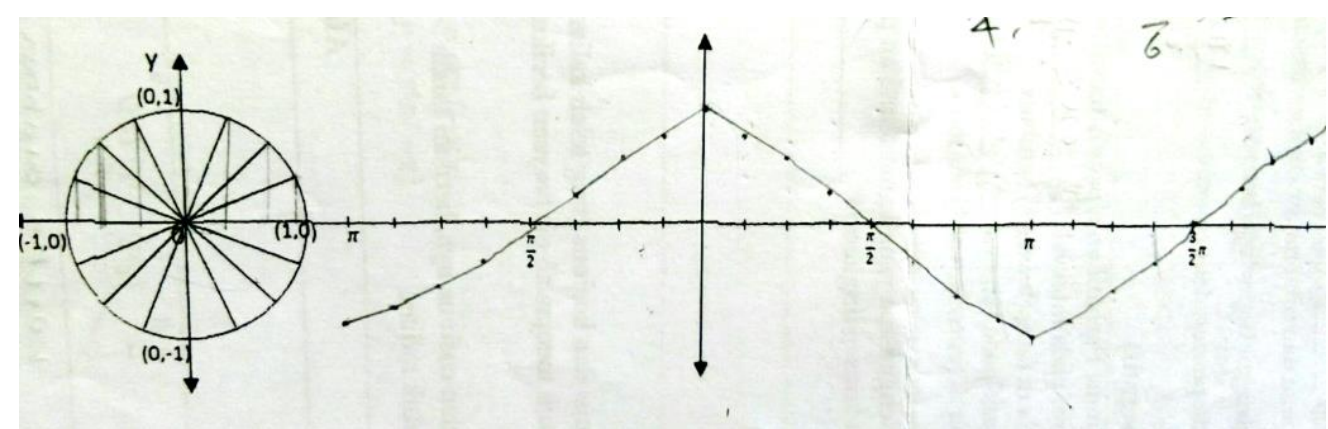

Figure 5. Student's is not drawing smooth curve on cosine function

When drawing tangent function some students got stuck in deciding the value in y-axis at the angle of $\frac{\pi}{2}$ and in the interval from $\frac{\pi}{2}$ to $\pi$, and $\frac{3 \pi}{2}$ to $2 \pi$. The value of tangent function at the angle of $\frac{\pi}{2}$ was described by the the teacher by involving the students to analyse it through the definition of tangent. The students got stuck in the angle of $\frac{\pi}{2}$ where one of the rays of $\alpha$ parallel to the the line $\overleftrightarrow{P^{\prime} Q^{\prime}}$. They could not find the intersection between $\overleftrightarrow{P^{\prime} Q^{\prime}}$ and the extension of two rays of $\alpha$. The students thought that it was impossible to draw the intersection lines since both lines are parallel as shown in student-teacher classroom interaction.

Students

: "How can I draw when the angle is $\frac{\pi}{2}$ ?"

Teacher : "Could you find the intersection?"

Students : "No, it is parallel.

Teacher

: "For this moment, you can draw vertical line to make a sign about this angle. Just continue drawing the other angle. We'll discuss this matter later"

The interaction between tacher and students is mentioned by (Kansanen \& Meri, 1999) as a pedagogical relation as the student and teacher bulid interaction relate to the material. The difficult situation that student experienced in angle $\frac{\pi}{2} \mathrm{rad}$ shows the adaptation and acculturation process. The student knew that they could not make the intersection in angle $\frac{\pi}{2} \mathrm{rad}$, thus they confuse in how to know the intersection point. However the teacher' response in hanging the answer reflects as a teacher role in devolution--to makes students accept mathematical responsibilities through problem solving without expressing the conclusions of learning first (Brousseou, 2002).

Student's mistake in drawing tangent function was in finding the value tangent in second and fourth quadrant i.e. they could not relate the angle from the unit circle to the cartesian plane (Figure 6). Further investigation revealed that the students failed to match between the angles and the tangent value. In the instruction, the students supposed to find the tangent values from continues to the anti-clockwise angles in a unit circle then corresponded them in Cartesian Plane.

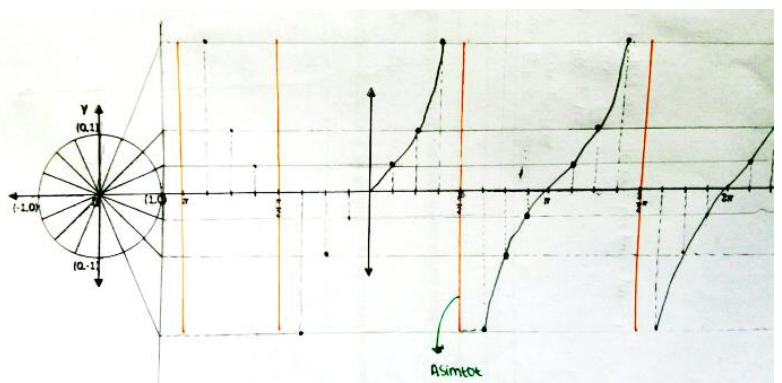

(a)

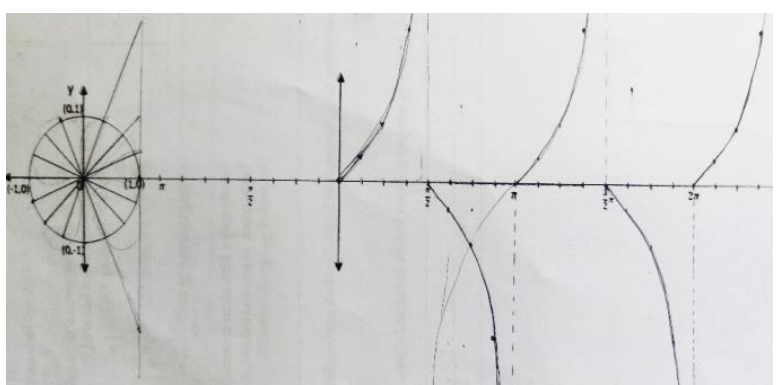

(b)

Figure 6. Student's work on drawing graph of $y=\tan (x)$, (a) true, (b) False

The anti-clockwise angles in the unit circle have been represented in the Cartesian plane as $x$-axis from the lowest to greatest. Contrarily, after they did the angle $\frac{\pi}{2}$, they continued to draw clockwise in fourth quadrant angles starting from the angle of $1 \frac{7}{8} \pi$. This method not only brought them to the false graph but also got them stuck in the second and third quadrant angles. This finding was outsode the context of the learning plan and contradict to the sine and cosine function which no issue found in drawing angles in second 
and fourth quadrant. However, Brousseou (2002) calls this situation as a-didactical situation, in which student interact in it as a key construct of adaptation.

The teacher foster the later institutionalization of the students' mathematical knowledge acquired during the a-didactical phase in drawing the tangent function and identifying a suitable set of problem situations that can support the development of new mathematical knowledge in analysing trigonometric function topic (see Figure 7).

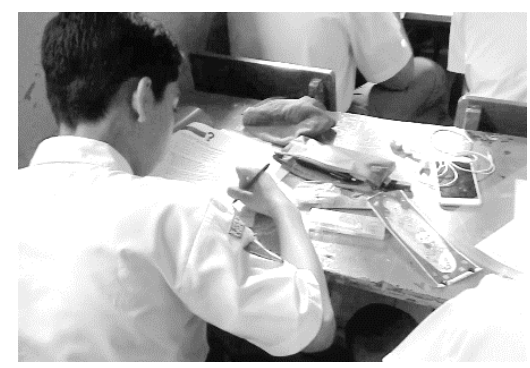

(a)

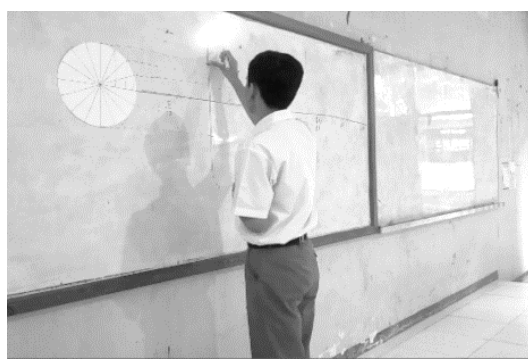

(b)

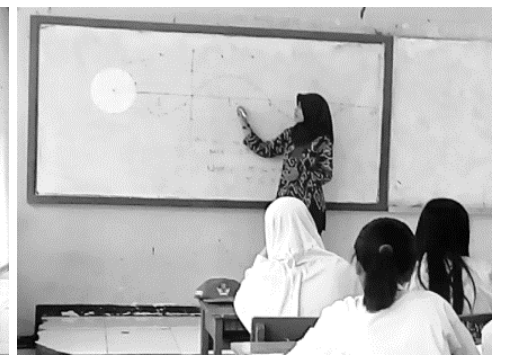

(c)

Figure 7. Students and teacher activities in the classroom

\section{Students' response in analysing the graph}

In analysing the graphs the students were guided by the students' worksheet and need need to answer the questions before they could discuss the answer with the teacher. Thus, the teacher can investigate the various of students' argumentation and analysis. Table $\mathbf{5}$ shows the findings of learning process when analysing the trigonometric function graph.

Table 5. Issues Found in Learning Process

\begin{tabular}{|c|c|c|c|}
\hline \multirow[t]{2}{*}{ Properties } & \multicolumn{3}{|l|}{ Issue Found } \\
\hline & Sine & Cosine & Tangent \\
\hline $\begin{array}{l}\text { Maximum \& } \\
\text { Minimum }\end{array}$ & Have no difficulty in finding the & $\begin{array}{l}\text { Have no difficulty in } \\
\text { finding the }\end{array}$ & Asymthot was introduced \\
\hline Period & $\begin{array}{l}\text { Some students false in determine } \\
\text { the period (because of } \\
\text { misunderstanding about the term of } \\
\text { period) }\end{array}$ & $\begin{array}{l}\text { Have no difficulty in } \\
\text { finding the period }\end{array}$ & $\begin{array}{l}\text { Having difficulty in finding } \\
\text { period. Students thought } \\
\text { that the period as same as } \\
\text { sine and cosine's }\end{array}$ \\
\hline \multirow{6}{*}{$\begin{array}{l}\text { Increasing \& } \\
\text { Decreasing }\end{array}$} & no significant difficulties & \multirow{2}{*}{$\begin{array}{l}\text { no significant } \\
\text { difficulties }\end{array}$} & \multirow{5}{*}{$\begin{array}{l}\text { Need further exploration in } \\
\text { studens' worksheet }\end{array}$} \\
\hline & how to get them to retain the & & \\
\hline & concept of trigonometric values & \multirow{2}{*}{$\begin{array}{l}\text { how to get them to } \\
\text { retain the concept of } \\
\text { trigonometric values }\end{array}$} & \\
\hline & $\begin{array}{l}\text { difficult in find for angle in fraction } \\
\text { representation because hard to }\end{array}$ & & \\
\hline & $\begin{array}{l}\text { determine the position of angle in } \mathrm{x} \text { - } \\
\text { axis }\end{array}$ & $\begin{array}{l}\text { difficult in find for } \\
\text { angle in fraction } \\
\text { representation }\end{array}$ & \\
\hline & a easier in find angles in degree & & \\
\hline
\end{tabular}

The maximum point for a function $y=\sin x$ or $y=\cos x$ is the point where $y$ has the largest value on an interval whereas the maximum point for a function $y=\sin x$ or $y=\cos x$ is the point where $y$ has the smallest value on an interval. Hence, the maximum and minimum value can be obtained from graphical representations by watching the highest and the lowest peak of the graph. Since both the sine and cosine function has the same maximum value $(+1)$ and minimum value $(-1)$, the sine and cosine have a range value from interval -1 to $+1,-1 \leq \sin x \leq 1$ and $-1 \leq \cos x \leq 1$. All of the students could answer these questions correctly. Although they had already known the maximum and minimum value from the unit circle concept they learned, besides, they could directly see the graph in which point the graph had the highest point and the lowest point. The students had no difficulty to find the maximum and minimum value of sine and cosine function through the graph representation since they easily notice from the peak of each graph. As Choi-koh (2003) finds that visual data facilitated the student's motivation to explain. In analysing tangent funxtion, 
students were introduced the asymptote and also the explanation of why they could not draw the graph when $x=\frac{\pi}{2}$ and its periodicity.

$\begin{array}{ll}\text { Teacher } & \text { : "what is the tangent value when } x=\frac{\pi}{2}, \\ \text { Students } & \text { : "Undefined" } \\ \text { Teacher } & \text { : "Why?" } \\ \text { Students } & \text { : (silence) }\end{array}$

In order to get the idea of the answer, the teacher was constructed task sequences as follows:

1) Recall the definition of tangent function i.e. sine over cosine

2) Calculate mathematically by substituting the value of $\sin \frac{\pi}{2}$ and $\cos \frac{\pi}{2}$

3) the final result showed that $\tan \frac{\pi}{2}=\frac{1}{0}$, which is undefine

This is a natural process of adaptation which involve imbalances to students in particular angle which differ from others (Artigue et al., 2014). Through this analysis of graphs of tangent functions students are introduced to the term asymptote, an asymptote is a straight line that is a close approximation to a particular curve as the curve goes off to infinity in one direction. The curve becomes very, very close to the asymptote line, but never touches it. For example, One of the asymptotes in tangent function is line $x=\frac{\pi}{2}$. Through this explanation the students were asked to figure out other asymptotes which could exactly determine by them. The classroom situation showed the relation among teacher, students and material as a didactical triangle Kansanen and Meri (1999). The competency of teacher in introducing the definition of asymptote in this situation shows the level competency of the teacher. It is important for the techer be able to view material from many side and approach (Kansanen, 2003). The students contructed formulation situation in which they argue and analyse the problem that they encounter.

The process of analyzing in which interval sine and cosine functions increasing or decreasing was a learning sequence to overcome students' obstacles in understanding the relationship between angles and their trigonometric values. For instance, the students assume that the greater the angle, the greater the sine value and vice versa in cosine (Weber, 2005). This assumption is correct in case of an acute angle, but it does not fit any angles. It only fits for particular interval angles. In comparing which sine value of two angles is greater than the other and comparing which cosine value of two angles is greater can be seen be seen from the distance of the graph to the $\mathrm{x}$-axis. If the distance of particular point on the sine/cosine value to the $\mathrm{x}$-axis is greater than the other point then so does the sine/cosine value. The graphical representtaion can comparing the value of $\sin 190^{\circ}$ and $\sin 27^{\circ}$ for example without knowing the exact value.

Teacher : :Be careful here, we pay attention to the sine graph and its angle, where is the location of the $\sin 190^{\circ}$ ? it is negative. So which one has greater value?"

Student : "sin $27^{\circ}$ "

The challenge appeared in how to get them to retain the concept of trigonometric values. In this case, several questions were provided in comparing the trigonometric values without knowing what the value is. In this type of questions, Through angles and providing an example, students can understand the relationship through analyzing from graphic representation. The students need to determine which one is greater by put the symbol more than $(>)$ or less than $(<)$ (all the angle is in radian). The students were encouraged to use trigonometric function graph to explore their answers.

1. $\sin (3,24) \ldots \sin (-1)$

2. $\cos \left(\frac{8}{3} \pi\right) \ldots \cos \left(\frac{7}{4} \pi\right)$

The obstacle came in when the angle appears as a fraction (e.g. $\frac{8}{3} \pi, \frac{7}{4} \pi$ ). They hardly determined where the right angle position in the $x$-axis. The students were still struggling in fraction particularly in comparing two or more fractions. This finding is differ when the students were provided the angle in degree unit which they did not find hard in determining the angle position in $x$-axis.

Periodic function is a function that keeps repeating the same values. Formally, a function $f(x)$ is periodic if there exist a number $p$ such that $f(x+p)=f(x)$, for all $x$. If $p$ is the smallest number with this property, then $p$ is called the period. The function of $y=\sin x$ is a periodic function with a period of $2 \pi$, because 
$\sin (x+2 \pi)=\sin x$, for all $x$ and so does $y=\cos x$ function. The class discussion in this material is presented below:

Teacher : "At what period does the graph repeat?"

Students : : $\pi$ " (some students)

: " $2 \pi$ " (the other some students)

Teacher : "Take a look! This curve is increasing and decreasing [pointing to the graph of the sine function], then it is increasing and decreasing again. So at what interval?"

Students : " $2 \pi$ ”

From the dialogue above it was known that some students were wrong to find the period of pi, the other were right. Differ from a study of Marchi (2012) that find the student uses memorized information to create the representation. Yet, in this study is more likely because of the lack of definition of period. They saw the graphical representation in interval $0 \mathrm{rad}$ to $\pi \mathrm{rad}$ was similar to the graphical representation in interval $\pi$ $\mathrm{rad}$ to $2 \pi \mathrm{rad}$ then they assumed that this was a repetition thus the period was $\pi \mathrm{rad}$. This reveals the lack relationship between students and the material of period which can affect didactical understanding (Kansanen, 2003; Kansanen \& Meri, 1999). In this situation the teacher controlled an activity in order to achieve the learning objective by giving the instruction to analyse based on the increasing and decreasing of the graph. This act as a teacher responsibility to direct the student-material relationship.

When analysing the tangent function, the students said that the period of the tangent was $2 \pi$ because in the two previous functions i.e. both sine and cosine function have periode of $2 \pi$. They did not analyze by the period definition first and then decide the answer.

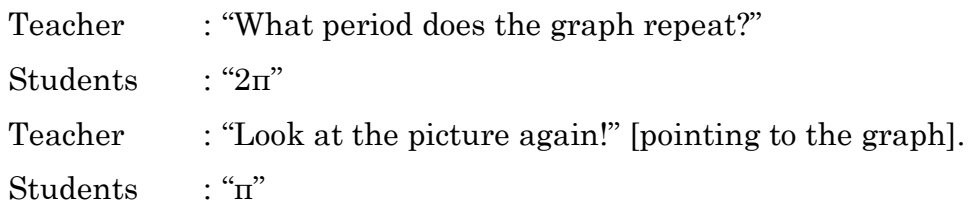

It is interesting that student said the period of tangent is $2 \pi$ because the two previous trigonometric functions (sine and cosine) has 2 п period. The memorized information used by the students in this situation was as same as what Marchi (2012). However, when the teacher asked them to look at the picture, the students noticed that the graph repeated in $\Pi$. The process of acculturation and adaptation of knowledge can be seen in this situation. The students had known the definition of period from the sine and cosine material, whereas they were distracted in finding the right answer because of the sine and cosine period. The process of didactical situation was shown when the student validated their answer into right answer after the process of action and formulation (Artigue et al., 2014).

\section{Retrospective Analysis}

Learning activities in a classroom is a complex system which involves several aspect of learning such as students, material, and teacher. The interaction among them is a huge exploration. This study was observing the interaction among the learning aspects using the didactical design which had been planned based on the learning theory. From the concept of didactical triangle propose by the (Kansanen, 2003; Kansanen \& Meri, 1999; Suryadi, 2018), the concept theory of didactical situation proposed by (Brousseau, 2002) and leanring hyphotesis by (Simon, 1995), the classroom situation in this study can be concluded as Figure 8 . The figure shows the didactical aspect which experienced by both the teacher and the students along the learning which is retrieved and devoleped from Artigue et al. (2014), Brousseau (2002), Kansanen and Meri (1999), and Suryadi (2013) explanation about classroom analysis. 


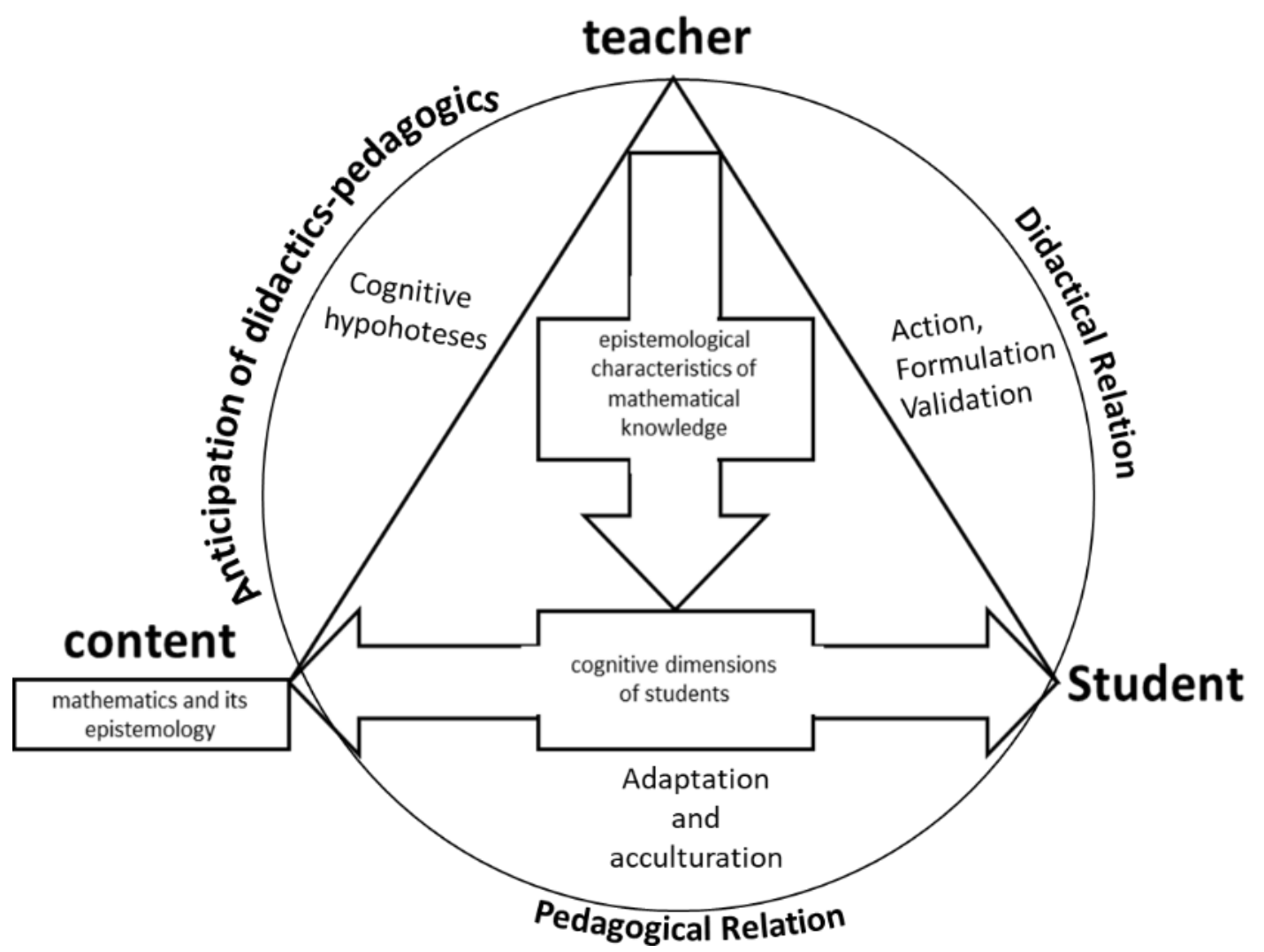

Figure 8. Didactical Situation Processes in Drawing and Analysing the Trigonometric Function Graphs

The didactical design in this study was able to demonstrate to the students how to draw the sine, cosine, and tangen function using the unit circle approach. However, the design can be enhanced in varying the examples and analysis to students especially in how to draw tangents. The learning sequences in analysing the trigonmetric graphs is quite comprehensive in sine and cosine functions which, however the tangent function need to be more explored by the teacher. In the design, the teacher did not provide varied examples which makes it difficult for students to determine the tangent value at another angle (example: quadrants II, III, and IV). The exploration of analysis in tangent function.

\section{CONCLUSION}

The didactical design in this study uses the unit circle approach through hands-on activity in drawing trigonometrics function graphs which dragging from the definition of the unit circle as well as analysing the properties of trigonometric function based on the graph they drew. The general idea in how the trigonometrics function can be drawn and analysed from the unit circle is ilustrated in Figure 9. 


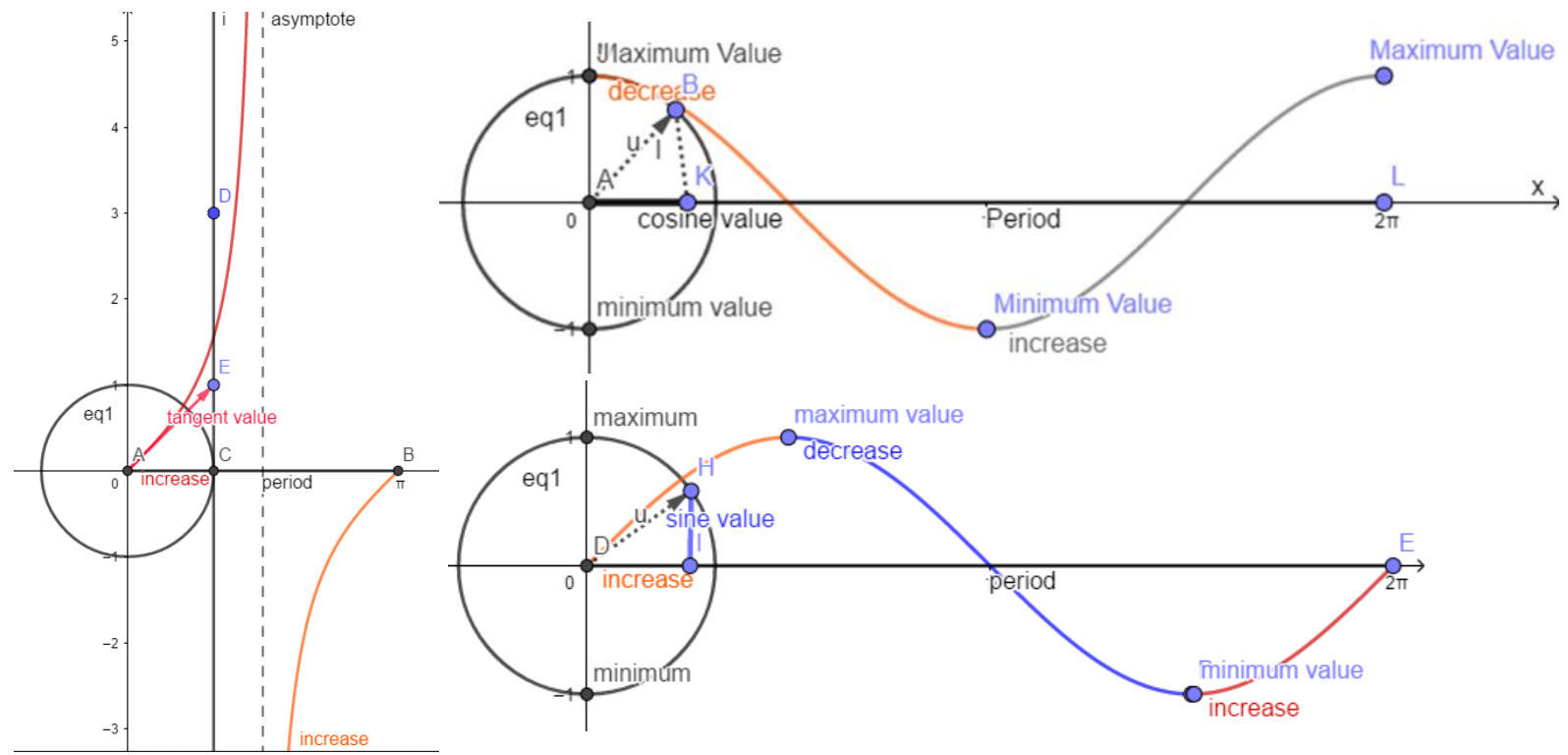

Figure 9. The idea in drawing and analysing sine, cosine and tangent function

In this instruction, the student need to understand the trigonometrics functions value in unit circle. Since the trigonometrics is a function, the students relate the correpondence of the domain and range representation to the graphical representation i.e. the lenght of the arc as a $\mathrm{x}$-axis and trigonometric value as a y-axis. Secondly, the student find the possible values of trigonometric function in the unit circle and tranfer them as dots into cartesian plan then connect the dots in smooth curve line. The trigonometric properties which are analysed in this study included maximum and minimum value, period, and increasing and decreasing function. The students use worksheet given in the learning process to help them aware of what trigonometric function properties should be analysed.

From the description in the results section, we can summarize the main findings. First, the study shows that the students can relates the interpretation of sine, cosine and tangent value in a unit circle to the graphical representation. In this design students have no difficulty in drawing cosine graphs because there are similarities with the process of drawing a graph of sine functions. This indicates that the process of drawing a sine graph is very attached to students. Unlike the sine and cosine function graph where the representation can be easily determined on the unit circle, in the tangent function it is necessary to construct the representation of the tangent value on the unit circle first uses the concept of congruence in triangles. Student can draw the graph well particularly when drawing the cosine function because the representation of the sine and cosine function is similar. The challenge exists when they draw a tangent function. It has not only different graphs from previous functions i.e. sine and cosine but also a complex process in figure out the representation in a unit circle. Many students need assistance in drawing the tangent graph.

Second, the implementation of the design has reached the learning objectives set. The retrospective analysis shows that this design should consider to use the angle in decimal form instead of fraction form since most of the students find difficulty in fraction especially comparing the value of fraction. For the teachers who intend to implement this design in classroom situation, they should pay more attention in sine function because the understanding of sine function related to the understanding of cosine function. The tangent function in unit circle is differ from sine and cosine thus the a-priori understanding in congruent triangles is helpful to have better understanding in this matter. Before applying this method the students have learned about trigonometry in a unit circle such as the degree measurement and the coordinate of a particular point in circle regarding the trigonometry.

Third, this study reveals that the situation in the class affects in how students perceive the mathematical content. However, the knowledge obtained by students in the class is not only students get from the situation created but also from information delivered directly by the teacher. So in this case, in addition to designing the design and conditioning the learning situation that will occur, the ability to communicate mathematical content to students becomes important. Thus, mathematics teacher is the creator of a didactic situation implemented in class should design the learning process in order to the students can obtain the expected knowledge. 


\section{LIMITATION AND FUTURE RECOMMENDATION}

The trigonometric functions material in this study is limited to sine, cosine and tangent function because the students have been familiar about those function in junior high school. Thus, further exploration in other functions such as secan, cosecan, and cotangent can be conducted in same classroom situation. The analyzes of the trigonometric function in this study are limited to maximum and minimu, increasing and decreasing function and period. The other properties of trigonometric functions, for instance, amplitude, will better to learn by students in more complex trigonometric functions since it can vary the exploration of function. Thus, further exploration of the trigonometric function graph properties needs to be conducted such as the amplitude and more complex trigonometric function graph which involve transformation. For further research, to put the domain side to the $\mathrm{x}$-axis from the unit circle, the teacher can use other techniques such as making a divided unit circle from paper then the students can wheel it through the x-axis while making a sign on it.

\section{ETHICS}

Regarding some ethical issues in this study such as ethical issues in research objectives, in collecting data, and in writing and publishing research results, the subject's weaknesses and strengts were presented objectively. Moreover, both the school and the teacher knew the purpose of this study. During and after the research process there are no activities that endanger the participants. The publication of the results of this study is intended for academic purposes and is limited to the academic environment to prevent data misuse

\section{ACKNOWLEDGEMENT}

This study was supported by the grant from Indonesia endowment fund for education (LPDP) number PRJ2161 /LPDP.3/2016. The opinions expressed are those of the researcher and do not necessarily represent the views of LPDP. We also thank to the school staffs and teacher for assistance and to the students who participated in this study.

\section{Disclosure statement}

No potential conflict of interest was reported by the authors.

\section{Notes on contributors}

Churun L Maknun - Institut Agama Islam Negeri Ponorogo, Indonesia, Universitas Wahidiyah, Indonesia, and Universitas Pendidikan Indonesia, Indonesia.

Rizky Rosjanuardi - Universitas Pendidikan Indonesia, Indonesia.

Al Jupri - Universitas Pendidikan Indonesia, Indonesia.

\section{REFERENCES}

Artigue, M. (2009). Didactical Design in Mathematics Education. In C. Winsløw (Ed.), Nordic Research in Mathematics Education (pp. 7-16). Rotterdam: Sense Publisher. https://doi.org/10.1163/9789087907839_003

Artigue, M., Haspekian, M., \& Corblin-Lenfant, A. (2014). Introduction to the Theory of Didactical Situations (TDS). In A. Bikner-Ahsbahs \& S. Prediger (Eds.), Networking of Theories as a Research Practice in Mathematics Education (pp. 97-113). Switzerland: Springer. https://doi.org/10.1007/978-3-319-05389-9

Ausubel, D. P. (1968). Educational psychology: A cognitive view. New York: Holt, Rinehart and Winston. https://doi.org/10.2307/1421346

Brousseau, G. (2002). Theory of didactical situations in mathematics (N. Balacheff, M. Cooper, R. Sutherland, \& V. Warfield, Eds.). New York: Kluwer Academic Publisher.

Bruner, J. S. (1960). The process of education. Cambridge, MA.: Harvard University Press.

Bruner, J. S. (1966). Toward a theory of Instruction. Cambridge, MA.: Belknap Press. https://doi.org/10.3726/978-1-4539-1735-0/12

Byers, P. (2010). Investigating Trigonometric Representations in the Transition to College Mathematics. College Quarterly, 13(2), 10. Retrieved from https://files.eric.ed.gov/fulltext/EJ930372.pdf 
Cetin, O. F. (2015). Students perceptions and development of conceptual understanding regarding trigonometry and trigonometric function. Educational Research and Reviews, 10(3), 338-350. https://doi.org/10.5897/ERR2014.2017

Choi-koh, S. S. (2003). Effect of a graphing calculator on a 10th-grade student's study of trigonometry. Journal of Educational Research, 96(6), 359-368. https://doi.org/10.1080/00220670309596619

Corlis, J. J., \& Berglund, W. V. (1958). Plane Trigonometry (second). Boston: The Riverside Press Cambridge.

Creswell, J. W. (2012). Educational Research: Planning, Conducting and Evaluating Quantitative and Qualitative Research (P. A. Smith, Ed., 4th Ed.). Boston: Pearson Education, Inc.

Creswell, J. W. (2013). Qualitative Inquiry \& Research Design: Choosing Among Five Approaches (3rd Ed.). California: SAGE Publication, Inc.

Demir, Ö., \& Heck, A. (2013). A new learning trajectory for trigonometric functions. In E. Faggiano \& A. Montono (Eds.), ICTMT11 (pp. 119-124). Bari: University of Bari. Retrieved from https://pure.uva.nl/ws/files/1802208/141597_A_new_learning_trajectory_for_trigonometric_functions. pdf

Gredler, M. E. (2004). Games and simulations and their relationships to learning. Handbook of Research on Educational Communications and Technology, 2, 571-581. https://doi.org/10.1109/BALTIC.2012. 6249194

Imsen, G. (1999). Reflection as a bridging concept between normative and descriptive approaches to didactics. TNTEE Publications, 2(1), 95-105. Retrieved from https://www.researchgate.net/profile/Brian_Hudson5 /publication/284365075_DidaktikFachdidaktik_as_the_Science-s_of_the_Teaching_Profession/links 156522cfb08ae1ef92975650d/Didaktik-Fachdidaktik-as-the-Science-s-of-the-Teaching-Profession.pdf

Kagenyi, D. G. (2016). Pedagogical factors affecting the learning of trigonometry in secondary schools in gatundu north sub-county (Unpublished Master's thesis). Kenyatta University, Kenya https://irlibrary.ku.ac.ke/bitstream/handle/123456789/11349/Pedagogical\%20factors\%20affecting\%20the\%20le arning $\% 20$ of $\% 20$ trigonometry $\% 20$ in $\% 20$ secondary ........pdf? sequence=3\&isAllowed $=y$

Kamber, D., \& Takaci, D. (2017). On problematic aspects in learning trigonometry. International Journal of Mathematical Education in Science and Technology, 5211(August), 1-15. https://doi.org/10.1080/0020739X.2017.1357846

Kansanen, P. (2003). Studying the Realistic Bridge Between Instruction and Learning: An attempt to a concentual whole of the teaching-Studying-learning process. Educational Studies, 29(2-3), 221-232. https://doi.org/10.1080/03055690303279

Kansanen, P., \& Meri, M. (1999). The Didactic relation in the teaching-studying-learning process. Didaktik/Fakchdidaktik as Science(-s) of the Teaching Profession?, 2(1), 107-116. Retrieved from https://www.researchgate.net/profile/Brian_Hudson5/publication/284365075_DidaktikFachdidaktik_a s_the_Science-s_of_the_Teaching_Profession/links/56522cfb08ae1ef92975650d/DidaktikFachdidaktik-as-the-Science-s-of-the-Teaching-Profession.pdf

Maknun, C. L., Rosjanuardi, R., \& Ikhwanudin, T. (2018). Students' Mathematical Argumentation in Trigonometry. In 5th International Conference on Education and Social Sciences (pp. 689-696). Istanbul: Ocerint. Retrieved from http://www.ocerint.org/intcess18_e-publication/papers/154.pdf

Maknun, C. L., Rosjanuardi, R., \& Jupri, A. (2018). Lesson design on the relationship between radian and degree. In AIP Conference Proceeding 2014, 020031 (2018) (pp. 020031-1-020031-020038). Surakarta: AIP Publishing. https://doi.org/10.1063/1.5054435

Maknun, C. L., Rosjanuardi, R., \& Jupri, A. (2019). From ratios of right triangle to unit circle: An introduction to trigonometric functions. In Journal of Physics: Conference Series (Vol. 1157). https://doi.org/10.1088/1742-6596/1157/2/022124

Marchi, D. J. (2012). A Study of Student Understanding of the Sine Function through Representations and the Process and Object Perspectives (Unpublished Master's thesis). Ohio State University, USA. Retrieved from https://etd.ohiolink.edu/!etd.send_file?accession=osu1343253667\&disposition=inline

Orhun, N. (2001). Student's Mistakes and Misconceptions on Teaching of Trigonometry. Journal of Curriculum Studies, (1), 208-211. Retrieved from http://math.unipa.it/ grim/AOrhun.PDF

Piaget, J. (1970). Generic epistemology. New York: Columbia University Press. New York: Columbia University Press. https://doi.org/10.7312/piag91272 
Ruthven, K., Laborde, C., Leach, J., \& Tiberghien, A. (2009). Design Tools in Didactical Research: Instrumenting the Epistemological and Cognitive Aspects of the Design of Teaching Sequences. Educational Researcher, 38(5), 329-342. https://doi.org/10.3102/0013189X09338513

Simon, M. A. (1995). Reconstructing mathematics pedagogy from a constructivist perspective. Journal for Research in Mathematics Education, 26(2), 114-145. https://doi.org/10.2307/749205

Spitzbart, A., \& Bardell, R. H. (1955). College Algebra and Plane Trigonometry. Massachusetts: AddisonWesley Publishing Company, Inc.

Sullivan, P., Knott, L., \& Yang, U. (2015). The Relationships Between Task Design, Anticipated Pedagogies, and Student Learning. In A. Watson \& M. Ohtani (Eds.), Task Design in Mathematics Education (pp. 83-114). Springer International Publishing Switzerland. https://doi.org/10.1007/978-3-319-09629-2_3

Suryadi, D. (2010). Penelitian Pembelajaran Matematika Untuk Pembentukan Karakter Bangsa [Research in Mathematics Education for Building National Character]. Prosiding Seminar Nasional Matematika Dan Pendidikan Matematika, (November), 1-14. Retrieved from http://eprints.uny.ac.id/10461/1/ 1Makalah\%5CnUtama\%5Cn-\%5CnDidi\%5CnSuryadi.pdf

Suryadi, D. (2013). Didactical Design Research (Ddr) Dalam Pengembangan Pembelajaran Matematika [Didactical Design Research (DDR) in Mathematics Research Development]. In A. Nurjaman, R. Sariningsih, I. P. Sari, \& G. Kadarisma (Eds.), Prosiding Seminar Nasional Matematika dan Pendidikan Matematika (pp. 3-12). Bandung: stkip siliwangi.

Suryadi, D. (2018). Landasan filosofis penelitian desain didaktis (DDR) (Januari) [Fundamental Philoshophy in Didactical Design Research]. Bandung.

Torrance, H. (2010). Qualitative Research Methods in Education (1st Ed.). SAGE Publication Ltd. https://doi.org/10.4135/9781446263174

Usman, M. H., \& Hussaini, M. M. (2017). Analysis of Students' Error in Learning of Trigonometry Among Senior Secondary School Students in Zaria Metropolis, Nigeria. IOSR Journal of Mathematics, 13(02), 01-04. https://doi.org/10.9790/5728-1302040104

Varberg, D., Purcell, E.J., dan Rigdon, S.E. 2006. Calculus, 9th edition. Pearson, New York.

Walsh, R., Fitzmaurice, O., \& O Donoghue, J. (2017). What Subject Matter Knowledge do second-level teachers need to know to teach trigonometry? An exploration and case study. Irish Educational Studies, 3315(June), 1-34. https://doi.org/10.1080/03323315.2017.1327361

Watson, A. (2015). Task Design in Mathematics Education. (M. Ohtani, Ed.). London: Springer. https://doi.org/10.1007/978-3-319-09629-2

Weber, K. (2005). Students' understanding of trigonometric functions. Mathematics Education Research Journal, 17(3), 91-112. https://doi.org/10.1007/BF03217423

Weber, K. (2008). Teaching trigonometric functions: lessons learned from research. Mathematics Teacher, 102(2), 144-150. Retrieved from https://pdfs.semanticscholar.org/11a0/70bdd2ee0752756fa7379554420 $87 \mathrm{f} 7 \mathrm{cafa0} . \mathrm{pdf}$ 